\title{
The Effect of Oscimum sanctum to the Thrombocytes Number on Mice
}

\author{
Yoni Astuti ${ }^{1}$, Rum Wijayanti ${ }^{2}$ \\ ${ }^{1}$ Biochemistry Department of Medical and Health Sciences, Universitas Muhammadiyah Yogyakarta, Indonesia \\ ${ }^{2}$ Medical and Health Sciences, Universitas Muhammadiyah Yogyakarta
}

\begin{tabular}{l}
\hline Article Info \\
\hline Article history: \\
Received Aug 19, 2015 \\
Revised Dec 22, 2015 \\
Accepted Jan 27, 2016 \\
\hline
\end{tabular}

\section{Keyword:}

Oscimum sanctum

Clopidogrel

Thrombocytes number

\begin{abstract}
Oscimum sanctum is herbal that was spread widely in Indonesia. Oscimum sanctum contains abundant of substances. One of the functions on Oscimum sanctum was anti-thrombocytes effect. This effect is associated with platelet function as a mechanical plug in the vascular injury during the normal homeostatic response. The disruption in thrombocytes function leads to disturb the blood clotting process. Therefore, The aims of the research were to prove the impact of Oscimum sanctum on the number of thrombocytes. This research used mice that divided into 3 groups, as a group I dose $250 \mathrm{mg} /$ day (Oscimum sanctum infusion), group II dose $500 \mathrm{mg} /$ day and the control group. We used clopidogrel as a positive control to determine the effectiveness of anti platelet effect. Data were analyzed by ANOVA showed that the existence of anti-thrombocyte effect in the Oscimum sanctum dose $500 \mathrm{mg} /$ day was significantly different. This result proved that Oscimum sanctum has anti-thrombocytes effect by decreasing thrombocytes number.
\end{abstract}

Copyright $@ 2016$ Institute of Advanced Engineering and Science. All rights reserved.

\section{Corresponding Author:}

Yoni Astuti,

Biochemistry Department of Medical and Health Sciences,

Universitas Muhammadiyah Yogyakarta, Indonesia.

Email : yoni_astuti@yahoo.co.id

\section{INTRODUCTION}

Oscimum sanctum are found everywhere in Indonesia. Oscimum sanctum has many functions including as food and traditional medicine, event Indonesian people use Oscimum sanctum more often as food than traditional medicine. In the health sciences Oscimum sanctum used to cure cough, to decrease heat of the body, anti-diarrhea, to cure insect bite, to make comfort during menstruation [1].

Oscimum sanctum contains eugenol, cineol, osimen, pinene, terpinhydrate, methyl chavicol, linalool, anethole, thymol, camphor, alanine, arginine, ascorbic acid, aspartic acid, benzyl acetate, $\beta$-carotene, $\beta$-sitosterol, Caffeic acid, carbohydrate, copper, cystine, eriodictyol, aesculetin, aeskulin, fat, fiber, geranyl acetate, glutamic acid, glycine, histidine, isoleucine, isoquercetin, leucine, lysine, magnesium, methionine, mersin, niacin, p-Coumaric acid, phytosterols, potassium, proline, quercetin, riboflavin, ruti, thiamine, tryptophan, tyrosine, valine, calcium, phosphorus, ferro and sulfur [2]. The substances have a function as medicine in Oscimum sanctum were essential oil, was found as dominant substances [3].

Currently, abundant reports were carried out to explore the substances and the function of Oscimum sanctum. In India, Oscimum sanctum were recommended to cure bronchitis, diarrhea, asthma bronchial, malaria, dysentery, dermatitis, arthritis, eye diseases, fever, insect bite, hepatoprotective, anticancer, antidiabetic, antispasmodic, antifungal, antimicrobial, analgesic, adaptogenic, antifertility, antiemetic, cardioprotective, diaphoretic [3]. Some reports were found that Oscimum sanctum have anti aggregasion trombocyes effect [3]-[6]. The effect was associated with the function of thrombocytes as a mechanical plug 
if vascular inflammatory occurred to respond normal homeostatis [7]. Disruption of thrombocytes aggregation leads to the clotting blood disturbances.

Ocimum basilicum is a family to Oscimum sanctum. This plant has substances similar with Oscimum sanctum but the concentration was different. Oscimum sanctum has an anti aggregation of thrombocytes effect. This effect was associated with the obstacle of thrombus generation regarding to thrombus malfunction [2],[4]. This study was conducted to prove the function of Oscimum sanctum, a family with Ocimum basilicum as resistor to the thrombocytes aggregation. How Oscimum sanctum interfere the number of thrombocytes was important to know to support the holistic medical.

\section{RESEARCH METHOD}

\subsection{Grouping the subject}

Sixteen male mice of swiss strain, \pm 20 grams body weight, 2 months old, were divided into 3 groups to treat with Oscimum sanctum infusion in different dose during 10 days. The aclimatitation for mice was a week. Groups 1 and 2 were treated as follows $250 \mathrm{mg} / \mathrm{day}, 500 \mathrm{mg} /$ day. Group 3 was positive control, treating by clopidogrel $(1.35 \mathrm{mg} / \mathrm{day})$. The blood was collected from mice tails $0.5 \mathrm{ml}$ at day 0 and day $10^{\text {th }}$. The research was conducted at Animal Laboratoy of Medical and Health Sciences of Universitas Muhammadiyah Yogyakarta.

\subsection{Thrombocyt analyses}

Thrombocytes number was detected by blood hematology analyzer at laboratorium penelitian dan pengujian terpadu (LPPT) Universitas Gadjah Mada. The calculation of thrombocyte number based on the phase-contrast methods. The calculation was repeated 5 times.

\subsection{Infusion preparation}

Twenty five grams Oscimum sanctum simplicia was heated into $150 \mathrm{ml}$ water $\left(90^{\circ} \mathrm{C}\right)$. After 15 minutes was cooled down.Water was filtered to seperate from the leaf. This infusa was $250 \mathrm{mg} / \mathrm{ml}$. The similar way to prepare $500 \mathrm{mg} / \mathrm{ml}$ of infusa, with the weight of simplicia $50 \mathrm{gr}$.

\subsection{Statistical analyses}

Data are presented as mean \pm SD. Comparisons between the control and the treatment groups also statistical significance were performed by using one-way ANOVA. Statistical significance was set upon $\mathrm{p}<$ 0.05 .

\section{RESULTS AND ANALYSIS}

There is a decreasing of thrombocytes number after treating with Oscimum sanctum infusion. The average of thrombocytes number at day 0 and day $10^{\text {th }}$ is shown in Table 1.

Table 1.The Average of Thrombocytes Number at Day 0 and Day $10^{\text {th }}$ after Treating with Oscimum sanctum Infusion

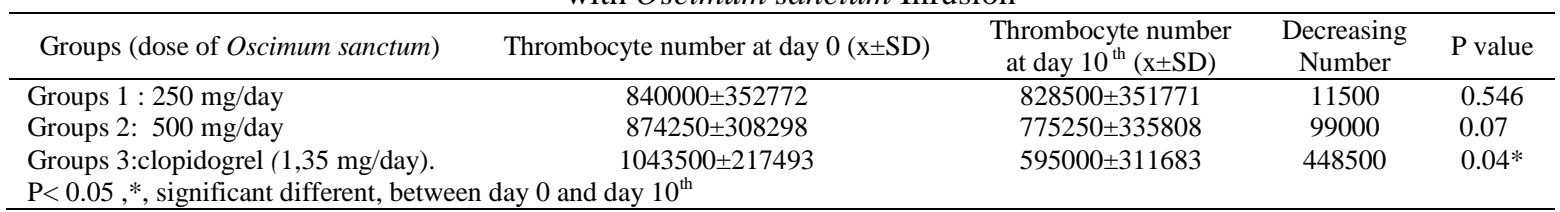

Table 1 shows that the highest on decreasing of thrombocytes number is clopidogrel group. Dose $500 \mathrm{mg} /$ day has higher effect than dose $250 \mathrm{mg} /$ day. The decreasing of the thrombocyte number on dose 250 $\mathrm{mg} /$ day was not significant statistically, but the Oscimum sanctum has an effect on the decreasing thrombocyte number. The clopidogrel was significant decreasing the thrombocytes number $(\mathrm{P}<0.005)$. This study found that Oscimum sanctum infusion and clopidogrel have a function to decrease thrombocytes number. In dose more than $500 \mathrm{mg} /$ day, probably has the same potentiality to clopidogrel. In this research showed that dose $500 \mathrm{mg} /$ day has lower potentiality to the standard dose, clopidogrel. Perhaps, the potentiality will be similar if the dose higher than $500 \mathrm{mg} /$ day. 
Percentage on decreasing thrombocytes number is linear to the dose of Oscimum sanctum infusion, more dose of Oscimum sanctum more decrease on thrombocyte number. Table 2 shows the potentiality of infusion Oscimum sanctum and clopidogrel to decrease the number of thrombocyte during 10 days .

Table 2. Potentiality of Infusion Oscimum sanctum and Clopidogrel on the Decreasing Thrombocyte Number

\begin{tabular}{lcc}
\hline Groups ( dose of b Oscimum sanctum infusion) & $\begin{array}{c}\text { Decreasing number } \\
(\mathrm{x} \pm \mathrm{SD})\end{array}$ & $\begin{array}{c}\text { Percentage of decreasing } \\
\text { number }(\%)\end{array}$ \\
\hline Dose: $250 \mathrm{mg} /$ day & $11500 \pm 4796$ & $1.52 \pm 1$ \\
Dose: $500 \mathrm{mg} /$ day & $99000 \pm 29944$ & $13.84 \pm 10$ \\
Clopidogrel & $448500 \pm 0$ & $45.72 \pm 18$ \\
\hline
\end{tabular}

The dose $500 \mathrm{mg} /$ day has $13,84 \%$ and the dose $250 \mathrm{mg} /$ day has much lower $1.52 \%$. Clopidogrel as a control has $45.72 \%$. This study used clopidogrelas positive control. Clopidogrel hydrogen sulfate, methyl $(+)-(S)-\alpha$-(o-chlorophenyl)-6,7-dihydrothieno[3,2-c]pyridin-5(4H)-acetate hydrogen sulfate, is a novel thienopyridine derivative that irreversibly blocks adenosine diphosphate (ADP) and is important in platelet aggregation, the cross-linking of platelets by fibrin [8]. Clopidogrel as a standard medicine for anti thrombocyte was common in public markets. Beside that, clopidogrel was compare with Oscimum sanctum infusion because both showed the effect after 7 days [3],[5],[9].

The comparison between potentiality of Oscimum sanctum infusion to clopidogrel has shown in Table 3. The potentiality of infusion in $500 \mathrm{mg}$ / day has $22.2 \% \mathrm{t}$ and $250 \mathrm{mg} /$ day $0.026 \%$ to clopidogrel. It was shown that the function will be significant with dose more than $500 \mathrm{mg} / \mathrm{ml}$. There was no meaning with dose less than $250 \mathrm{mg} / \mathrm{ml}$.

Table 3. Comparasion of the Potentiality Oscimum sanctum Infusion to Clopidogrel on Decreasing Thrombocyte Number

\begin{tabular}{cc}
\hline Groups & Percentage (\%) thrombocytes number \\
\hline Group 1: 250mg/day / clopidigrel & 2.5641 \\
Group 2:500mg/day/clopidogrel & 22.07358 \\
\hline
\end{tabular}

Table 3 describes that double dose of Oscimum sanctum infusion compare to clopidogrel result in effect around 10 times stronger on decresing trombocytes number. But it does not mean that $1000 \mathrm{mg} / \mathrm{day}$ Oscimum sanctum infusion will has effect 100 times stronger than $250 \mathrm{mg} / \mathrm{day}$.

Since Singh et al, 2007 reported that oil of Oscimum sanctum has the effect of anticoagulant by inhibition of TXA2 through cyclooxygenase and produces PGI3 and TXA3. Like PGI2, PGI3 have antiaggregatory property while TXA3 has much less antiaggregatory. Thus, both of subtances work concurrently to contribute the anticoagulant effect on oil of oscium sanctum ${ }^{4}$. We use infusion because the substances of infusion more complete and the concentration higher. Eugenol in Oscimum sanctum was $40 \%$ [1],[3] and able to obstruct thrombocytes agreggration by inhibition on arachidonat acid, collagen, epinephrine, ADP to induce thrombocytes aggregation [10]. The inhibition on such ways leads to inhibit on the increasing of collagen, ADP and $\mathrm{Ca}^{2+}$ as regulatoron the function of thrombocytes.

The thrombocytes regulator substances were divided into 3 groups. Collagen was the first agents that formed outside of thrombocytes and interact with receptors on thrombocyte membrane. ADP was second groups as agent that formed inside of thrombocytes and interact with receptors membrane, meanwhile the $\mathrm{Ca}^{2+}$ as the third group as agent that formed inside of thrombocytes and work inside [7]. In this situation if the vascular endothel damage, ADP did not invole in the increasing of thrombocytes aggregation. Nevertheless thrombocytes aggregation still occurred, thrombocyt did not produced signalling substances on fibrin formation to encourage thrombocytes plug that already avaiabled and also collagen was hampered to act as a mark on fibrin formation. With the result that thrombocytes in blood will be reduced which causes bleeding time longer.

The other report showed that Oscimum sanctum also contains of methanolic substances that have an antiatherogenic effect, as called Caps HT2 or HT2 blocker. Caps HT2 has a function as an antioxidant, anticoagulant, antiageggration of thrombocytes, releasing lipoprotein lipase, anti-inflammation agent, and activate of hipolipidemic on mice [6]. Oscimum sanctum also have flavonoids. as shown in Melothria maderaspatana. Methanolic and flavonoid were extracted with hexane able to inhibit thrombocyte aggregation [11]. It was assumed that the effect of thrombocytes aggregation due to methanolic and flavonoids activity. The mechanism as antiagreggation on thrombocyt by methanolic was poor understood. Whereas the mechanism of flavonoids on the inhibition of thrombocytes was mediated with the increasing of 
cyclic AMP (platelets' cyclic AMP levels) by stimulate adenylate cyclase also inhibited cAMP phosphodiesterase [6].

Flavonoids impede the adhesion and ageggration of thrombocytes, beside of releasing the calcium sitoplasmic to stimulate the releasing of ADP and 5HT. Serotonin (5HT) was released by thrombocyte to stimulate ageggration and vasoconstriction [10]. The inhibition on this mechanism by flavonoid, result in the inhibition of thrombocytes ageggration due to the inhibition from eugenol also. The inhibition on vasoconstriction induced to the complicacy on thrombocytes plug formation, lead to the bleeding time longer. The similar effect made by eugenol. Wherefore the inhibition of thrombocyte aggregation by eugenol, methanolic and flavonoid induced in the decreasing of thrombocyte number. Perhaps, this mechanism results in the execcive of thrombus formation inhibition by the adhesion and thrombocytes aggregation. This study showed that Oscimum sanctum have a function as an alternative anti thrombocytes medicine [10].

\section{CONCLUSION}

Oscimum sanctum have a thrombocytes anti ageggrations by lowering the thrombocytes number. The dose of Oscimum sanctum more than $500 \mathrm{mg} /$ day could have the similar effect to clopidogrel on the lowering of thrombocytes number. Oscimum sanctum could as the alternative medicine as the thrombocytes anti ageggration.We suggest for further research: (1) to explore the higher dose of Oscimum sanctum infusion more than $500 \mathrm{mg} /$ day to find the similar potentiality with standard dose on clopidogrel, (2) to explore the other liquid than water to extract Oscimum sanctum to produce the concentrated extraction, (3) the mechanisme of decreasing the thrombocyt number still need explrored.

\section{ACKNOWLEDGEMENTS}

We are thanks to Animal Laboratory Universitas Muhammadiyah Yogyakarta and LPPT Universitas Gadjah Mada to help our research.

\section{REFERENCES}

[1] Dewi, SP., "Oscimumsantum", Tanaman Obat Indonesia, 2007. toiusd.multiply.com.

[2] Khan, IN., Habib, R., Rahman, R., Mannan, A., Sarker, MI, Hawlader S., "Thrombolitic Potential of Oscimunsactum L, Curcuma Longa,L,AzadirachtaindicaL,andAnacardiumoccidentale L", Journal Of Basic and Clinical Pharmacy, vol/issue: 2(3), pp. 125-127, 2011.

[3] Prakash, H., Gupta, N., "Therapeutic Uses of Oscimum sanctum Linn (Tulsi) with a Note on Eugenol and Its Pharmalcological Actions", Indian Journal Physiology Pharmacology, vol/issue: 49(2), pp. 125- 31, 2005.

[4] Singh, S., Rehan, HMS., Majumdar, DK., "Effect of Oscimum sanctum fixed oil on blood pressure, blood clotting time and pentobarbitone-induced sleeping time", Journal of Ethnopharmacology, vol/issue: 78(2-3), pp. 139-143, 2001.

[5] Tohti, I., Tursun, M., Umar, A., Turdi, S., Imin, H., Moore, N., "Aqueous extracts of Ocimumbasilicum L. (sweet basil) decrease platelet aggregation induced by ADP and thrombin in vitro and rats arterio-venous shunt thrombosis in vivo", Thrombosis Research, vol/issue: 118(6), pp. 733-739, 2006.

[6] Mary, NK., Babu, BH., Padikkala, J., "Antiatherogenic effect of Caps HT2, a herbal Ayurvedic medicine formulation", Phytomedicine, vol/issue: 10(6-7), pp. 474-482, 2003.

[7] Sama, SN., "A Mine of Medical Uses : Ocimum Sanctum, The Holy Basil", Internasional Journal Review and Research, vol/issue: 2(2), pp. 69-74, 2012.

[8] El-Sadek MEH., Moustafa SM., Kadi HO., Al-Hakami AMA., "Determination of Clopidogrel Carboxylic Acid in Human Plasma by LC-MS/MS", American Journal of Analytical Chemistry, vol. 2, pp. 447-455, 2011.

[9] Katzung, BG., "Basic and Clinical Pharmacology (8th ed)", (D. Sjabana, E. Isbandiati, A. Basori, M. Soedjak, I. Uno, Ramadhani, S. Zakaria, penerjemah), Jakarta, Salemba Medika, 2002.

[10] Chen, SJ., Wang, MH., Chen, IJ., "Antiplatelet and calcium inhibitory properties of eugenol and sodium eugenol acetate", Gen Pharmacology, vol/issue: 27(4), pp. 629-33, 1996.

[11] Iman RA., "The effect of Melothriamaderaspatanainhibit in platelet aggregation", Indian Journal of Pharmaceutical Sciences, vol/issue: 68(5), pp. 668-670, 2006. 